\title{
Qualidade de pães com farelo de arroz torrado
}

\author{
Quality of breads with toasted rice bran
}

\author{
Manoel Soares SOARES JÚNIOR ${ }^{2 *}$, Priscila Zaczuk BASSINELLO ${ }^{1}$, \\ Márcio CALIARI ${ }^{2}$, Pedro Francisco Cavalcante GEBIN ${ }^{2}$, Thais de Lima JUNQUEIRA ${ }^{2}$, \\ Vinícius Almeida GOMES², Diracy Bethânia Cavalcante Lemos LACERDA²
}

\section{Resumo}

O objetivo deste trabalho foi avaliar a qualidade de pães de fôrma formulados com diferentes níveis de substituição de farinha de trigo (FT) por farelo de arroz torrado (FAT). Utilizou-se um delineamento inteiramente casualizado, um tratamento controle e quatro tratamentos (7,5, 15,0, 22,5 e 30,0\% de substituição de FT por FAT) e três repetições. Avaliaram-se a aceitabilidade (aparência, textura e sabor), o volume específico, a composição centesimal e o valor calórico de cada tratamento. Entre os pães formulados com FAT, o tratamento com 7,5\% de substituição de FT por FAT obteve o maior volume específico $\left(3,37 \mathrm{~cm}^{3} \cdot \mathrm{g}^{-1}\right)$, não diferindo do tratamento controle em relação às notas sensoriais de aparência $(7,23)$, sabor $(7,08)$ e textura $(7,52)$. Em relação à composição centesimal, o tratamento com $7,5 \%$ de substituição obteve, quando comparado ao tratamento controle, um acréscimo de $26,02 \%$ de fibras totais, $34,85 \%$ de fibras insolúveis, $11,26 \%$ de fibras solúveis, $52,70 \%$ de lipídios, $53,33 \%$ de cinzas, $8,21 \%$ de umidade e uma redução de 8,36\% de carboidratos, 8,85\% de proteínas e 3,57\% no valor calórico. Pães de fôrma formulados com 7,5\% de substituição de FT por FAT podem ser uma alternativa viável de inclusão de um produto fonte de fibras e com menor valor calórico no mercado consumidor.

Palavras-chave: Oryza sativa L.; subproduto; desenvolvimento de produtos.

\begin{abstract}
The aim of this work was to evaluate the quality of breads formulated with different levels of toasted rice bran (FAT) in a mixture with wheat flour (FT). A completely randomized design was applied including one control and four treatments $(7.5,15.0,22.5$, and 30.0\% substitution of FT by FAT) and three repetitions. The acceptability (appearance, texture, and flavor), specific volume, centesimal composition, and caloric value of each treatment were evaluated. Among the breads formulated with FAT, the treatment using 7.5\% FAT presented the highest specific volume $\left(3.37 \mathrm{~cm}^{3} \cdot \mathrm{g}^{-1}\right)$, which did not differ from the control treatment in terms of appearance (7.23), flavor (7.08) and texture (7.52) sensory scores. Regarding the centesimal composition, the treatment with $7.5 \%$ substitution, when compared to the control, presented an increase of $26.02 \%$ in the total dietary fiber, $34.85 \%$ in insoluble fibers, $11.26 \%$ in soluble fibers, $52.70 \%$ in lipids, $53.33 \%$ in ash, $8.21 \%$ in moisture and a reduction of $8.36 \%$ in carbohydrates, $8.85 \%$ in proteins, and $3.57 \%$ in the caloric value. Pan bread elaborated with $7.5 \%$ toasted rice bran in replacement of wheat flour could be a viable alternative to include a fiber-rich and low-calorie product in the market.
\end{abstract}

Keywords: Oryza sativa L.; byproduct; product development.

\section{Introdução}

O arroz é o segundo cereal de maior produção e consumo no mundo, com maior cultivo nos países asiáticos, sendo o Brasil, excetuando-se esses países, o maior produtor desse grão (FAO, 2005). O farelo de arroz, camada superficial do grão integral, é obtido durante o polimento do grão para obtenção do arroz branco, principal forma de consumo deste cereal. Representa $8 \%$ do grão em casca e possui conteúdos variáveis de amido provenientes do endosperma, de resíduos de casca e de fragmentos de grão, sendo, portanto, um subproduto que possui teores variáveis de nutrientes, dependendo do sistema de beneficiamento, do grau de polimento dado ao arroz, do tratamento do grão antes do beneficiamento e da cultivar (SAUNDERS, 1990).

O aproveitamento dos subprodutos do beneficiamento do arroz no Brasil ainda é incipiente e pouco diversificado. A casca e o farelo ainda são vistos como sinônimos de poluição ambiental (CARVALHO; BASSINELLO, 2006). Nas regiões onde o arroz é altamente consumido, grandes quantidades de farelo são desprezadas. Entretanto, o farelo de arroz é uma excelente fonte de fibras, vitaminas, minerais, proteínas e lipídios. As fibras do farelo de arroz possuem boa capacidade de absorção de água e óleo e, por isso, podem contribuir para o desenvolvimento de uma enorme variedade de produtos industrializados que requerem estas propriedades (SAUNDERS, 1990), embora a textura fibrosa, a liberação de ácidos graxos e a fácil rancificação sejam fatores que têm restringido sua utilização na alimentação humana até o momento (ALENCAR; ALVARENGA, 1991).

Vários pesquisadores têm estudado a inativação das lipases, enzimas que provocam o aumento rápido e acentuado da acidez do óleo do farelo de arroz. A aplicação do calor é o método

Recebido para publicação em 13/12/2007

Aceito para publicação em 28/10/2008 (003096)

${ }^{1}$ Centro Nacional de Pesquisa de Arroz e Feijão - CNPAF, Empresa Brasileira de Pesquisa Agropecuária - Embrapa, CEP 71246-902, Santo Antônio de Goiás - GO, Brasil

${ }^{2}$ Engenharia de Alimentos, Universidade Federal de Goiás - UFG, CEP 74001-970, Goiânia - GO, Brasil, E-mail: manoel@agro.ufg.br

${ }^{*}$ A quem a correspondência deve ser enviada 
mais seguro e eficiente para manter a qualidade e o alto valor industrial, uma vez que as enzimas lipolíticas e oxidativas, os microrganismo e os agentes tóxicos naturais no farelo são termicamente lábeis (SILVA; SANCHES; AMANTE, 2006). O farelo de arroz pode ser torrado, ou seja, tratado termicamente a temperaturas na faixa de $100-110^{\circ} \mathrm{C}$, em panela em fogo direto, por cerca de 10 minutos. A composição química do farelo de arroz in natura não apresentou diferença significativa em relação à do farelo de arroz torrado (FAT), exceto em relação à umidade e aos lipídios (ALENCAR; ALVARENGA, 1991).

Frações de farelo de arroz, com baixo e alto conteúdo de fibras, foram incorporadas com êxito em vários níveis de substituição à farinha de trigo para a fabricação de pão. A qualidade da peça de pão, tipo francês, fabricado com essas misturas se compara favoravelmente com a de pães formulados com misturas de farinha de trigo (FT) e de centeio. Ainda que a cor seja escura e o volume menor que o normal, os pães têm aroma e sabor suaves e agradáveis. É dito que este farelo apresenta propriedades únicas, quando comparado a outros farelos de cereais, quanto ao seu emprego em panificação (BARBER; BARBER; MARTÍNEZ, 1981).

Saunders (1990) cita diversos produtos que se utilizam do farelo de arroz: pães, muffins, bolos, biscoitos e tortas. Entretanto, na literatura científica foram encontrados poucos estudos sobre as aplicações do farelo de arroz em produtos para a alimentação humana, a aceitabilidade e a composição nutricional desses produtos. O objetivo deste trabalho foi avaliar a qualidade física, química e sensorial de pães de fôrma formulados com diferentes níveis de substituição da FT por FAT.

\section{Material e métodos}

Este estudo foi realizado nos Laboratórios de Panificação, Análise Sensorial e Análises Físico-Químicas de Alimentos (Escola de Agronomia e Engenharia de Alimentos da UFG, Goiânia-GO) e de Tecnologia de Alimentos (Embrapa Arroz e Feijão, Santo Antônio de Goiás-GO). O farelo de arroz foi doado pela empresa Cristal Alimentos Ltda., localizada no Município de Aparecida de Goiânia, GO. Os demais ingredientes utilizados na formulação dos pães (farinha de trigo especial Lunar, leite em pó Leite Bom, sal comum Nevado, açúcar cristal Sabor Cristal, melhorador para farinhas e antimofo Itaiquara, margarina com 65\% lipídios Delícia e fermento fresco Fleischmann) foram adquiridos no comércio local de Goiânia-GO.

O farelo de arroz foi torrado no mesmo dia em que foi obtido, em bateladas de $500 \mathrm{~g}$, utilizando-se panela (diâmetro de $40 \mathrm{~cm}$ e altura de $20 \mathrm{~cm}$ ) em fogo direto e colher de aço inoxidável para mexer, a uma temperatura aproximada de $110{ }^{\circ} \mathrm{C}$ (medida com termômetro a laser), por 10 minutos, sendo, em seguida, peneirado e embalado em saco laminado (polietileno/nylon/polietileno) a vácuo e armazenado à temperatura de $-18{ }^{\circ} \mathrm{C}$, conforme método descrito por Alencar e Alvarenga (1991).

Utilizou-se um delineamento inteiramente casualizado (DIC), com um controle e quatro tratamentos $(7,5,15,0,22,5$ e 30,0\% de substituição da FT por FAT) e três repetições. O tratamento controle foi formulado com $3000 \mathrm{~g}$ de FT e sem
FAT, enquanto que os demais, no percentual e ordem citados anteriormente, utilizaram 2775 e 225 g, 2550 e 450 g, 2325 e 675 g, 2100 e 900 g de FT e FAT. Os demais ingredientes (dos mesmos lotes de fabricação) permaneceram constantes: sal (60 g), açúcar (180 g), fermento (150 g), margarina (120 g), leite em pó (60 g), melhorador (12 g) e antimofo (4 g). Utilizou-se água gelada, suficiente para dar o ponto de véu à massa. Para o processamento dos pães, utilizou-se o método direto de panificação, padronizando-se os seguintes procedimentos: mistura e amassamento por 25-30 minutos em batedeira Superfecta, modelo BT-20; divisão e pesagem manual da massa (700 g); moldagem manual; fermentação por 1 hora e 45 minutos em armário de fermentação; e cozimento em forno de lastro Superfecta, modelo SC-23, por 45 minutos à temperatura de $160 \pm 5^{\circ} \mathrm{C}$, conforme descrito por Soares Júnior et al. (2006).

Após cada fornada, os pães permaneceram à temperatura ambiente durante uma hora. A seguir, foram determinados a massa ( $\mathrm{g})$, o volume $\left(\mathrm{cm}^{3}\right)$ e o volume específico de cada amostra, utilizando-se uma balança digital semianalítica e o método de deslocamento de sementes de painço para a determinação da massa e do volume, sendo o volume específico calculado conforme descrito em Silva, Silva e Chang (1998).

Um dia após ser assado, cada tratamento foi avaliado por meio do teste de aceitabilidade, por 100 consumidores potenciais do produto, selecionados em função da disponibilidade e interesse em participar da análise sensorial. A degustação foi realizada em nível laboratorial, em cabines individuais, com as amostras servidas de forma monádica. Os parâmetros de aparência, textura e sabor foram avaliados com o auxílio de escala hedônica estruturada mista de 9 pontos, variando de 1 para "desgostei extremamente" e 9 para "gostei extremamente" (FARIA; YOTSUYANAGI, 2002).

Os teores de umidade, proteínas, lipídios e cinzas de cada tratamento foram determinados segundo as normas descritas pelo Instituto Adolfo Lutz (2005): o teor de umidade em estufa a $105^{\circ} \mathrm{C}$, até peso constante; o nitrogênio pelo método de micro Kjeldahl e convertido em proteína bruta pelo fator 6,25; as cinzas por incineração em mufla a $550{ }^{\circ} \mathrm{C}$; os lipídios por extração direta em Soxhlet. As fibras alimentares solúvel, insolúvel e total foram determinadas por método enzímicogravimétrico, baseado no método oficial n. ${ }^{\circ} 985.29$ da AOAC International (1997). Os carboidratos foram calculados por diferença, subtraindo-se de 100 os valores encontrados para umidade, proteína, lipídios, fibra alimentar total e cinzas. Os valores calóricos totais foram calculados multiplicando-se as porcentagens de lipídios, proteínas e carboidratos de cada amostra pelos seus valores calóricos respectivos: 9, 4 e 4 kcal fatores de conversão de Atwater, segundo Merril e Watt apud Wilson et al. (1982). Todas as análises químicas foram realizadas em triplicata.

Os resultados foram avaliados por meio de análise de variância e as médias foram comparadas entre si pelo teste Tukey, ao nível de $5 \%$ de probabilidade (PIMENTELGOMES, 2000). 


\section{Resultados e discussão}

As médias de volume específico e os escores médios para aparência, textura e sabor dos tratamentos com diferentes níveis de substituição de FT por FAT estão apresentados na Tabela 1.

Em relação ao volume específico, os tratamentos diferiram entre si $(\mathrm{p} \leq 0,05)$, com exceção das médias dos tratamentos com 7,5 e 15,0\% de substituição de FT por FAT, que não diferiram entre si. O tratamento controle obteve o maior volume específico $\left(4,43 \mathrm{~cm}^{3} \cdot \mathrm{g}^{-1}\right)$, enquanto que o menor foi observado no tratamento com $30,0 \%$ de substituição $\left(2,70 \mathrm{~cm}^{3} \cdot \mathrm{g}^{-1}\right)$. Verificouse que, quanto maior a substituição de FT por FAT, menor o volume específico do pão de fôrma, como pode ser visualizado claramente na Figura 1.

Gutkoski et al. (2005) afirmaram que o volume específico representa, com bastante precisão, a variação de volume dos pães. O volume específico médio encontrado por estes autores para pães de fôrma tradicionais foi de $4,41 \mathrm{~cm}^{3} \cdot \mathrm{g}^{-1}$, muito próximo ao encontrado neste trabalho $\left(4,43 \mathrm{~cm}^{3} \cdot \mathrm{g}^{-1}\right)$. $\mathrm{O}$ volume específico mostra claramente a relação entre o teor de sólidos e a fração de ar existente na massa assada. Pães com volumes específicos baixos (embatumados) apresentam aspecto desagradável ao consumidor e estão associados com alto teor de umidade, falhas no batimento e na cocção, pouca aeração, difícil mastigação, sabor impróprio e baixa conservação (ESTELLER; LANNES, 2005).

$\mathrm{Na}$ análise sensorial dos pães, 51\% dos consumidores entrevistados tinham entre 21-25 anos, 43\% entre 15-20 anos, $3 \%$ entre $26-30$ anos e $3 \%$ acima de 30 anos, sendo $56 \%$ do sexo feminino e $44 \%$ do sexo masculino. O percentual de consumidores entrevistados com consumo mensal entre 1 e 5 pães de fôrma foi de 33\%, entre 6 e 15 unidades foi de $46 \%$ e acima de 16 unidades foi de $21 \%$.

Os tratamentos controle e com 7,5\% de substituição não diferiram entre si $(\mathrm{p}>0,05)$ em relação à aparência, obtendo os melhores escores, entre 7 e 8 (gostei regularmente a gostei muito). Os tratamentos com 15,0 e 22,5\% de substituição também não diferiram entre si ( $\mathrm{p}>0,05)$, ficando as médias entre 6 e 7 , ou seja, entre gostei ligeiramente a gostei regularmente, enquanto que o tratamento com $30,0 \%$ de substituição obteve o menor escore $(5,51)$, entre indiferente e gostei ligeiramente, devido ao seu alto escurecimento, comprovando que pães de fôrma escurecidos são rejeitados pelos consumidores. $\mathrm{O}$ tratamento térmico que provavelmente estabilizou o farelo de arroz o fez adquirir uma coloração mais escura que a da FT. A substituição parcial de FT por FAT na formulação dos pães de fôrma agregou a estes parte da coloração do FAT. Nabeshima et al. (2005) dizem que a alteração de cor nos pães altera diretamente sua aparência e isso pode acarretar um aumento da rejeição por parte dos consumidores. Assim, uma substituição de até 7,5\% de FT por FAT não foi suficiente para prejudicar significativamente a aparência do pão (Figura 1).

Com a elevação gradual do grau de substituição de FT por FAT ocorreu uma diminuição nos escores médios de textura. $\mathrm{O}$ tratamento controle não diferiu $(p>0,05)$ em relação à textura do tratamento com $7,5 \%$ de substituição. O mesmo ocorreu entre os tratamentos com 15,0 e 22,5\% de substituição e entre os tratamentos com 22,5 e 30,0\% de substituição. As características tecnológicas das fibras e seus efeitos sobre outros componentes do alimento são problemas encontrados na formulação de produtos funcionais com alto teor de fibra (CARVALHO, 1995). Portanto, torna-se evidente a necessidade de adequar um maior nível de fibra com a menor mudança possível nas características sensoriais (principalmente texturais) dos novos alimentos, tornando o produto aceitável pelo consumidor. Neste trabalho, o tratamento com 7,5\% de substituição de FT por FAT foi o mais aceito em relação à textura.

Em relação ao sabor, o tratamento controle não diferiu do tratamento com $7,5 \%$ de substituição de FT por FAT, obtendo os maiores escores médios (entre 7 e 8 , gostei moderadamente a gostei muito). Mas ambos diferiram $(\mathrm{p} \leq 0,05)$ dos demais tratamentos, que por sua vez, diferiram $(\mathrm{p} \leq 0,05)$ entre si. $\mathrm{O}$ pão com $30 \%$ de substituição apresentou a menor nota média para sabor (entre 4 e 5), equivalente a desgostei ligeiramente a indiferente, portanto, não foi aceito pelos consumidores. Alencar e Alvarenga (1991), afirmam que a adição de até $20 \%$ de FAT aos alimentos não modifica seu sabor, podendo substituir parcialmente outras farinhas no preparo de pães, bolos, tortas, biscoitos e outras formulações, o que contradiz os resultados

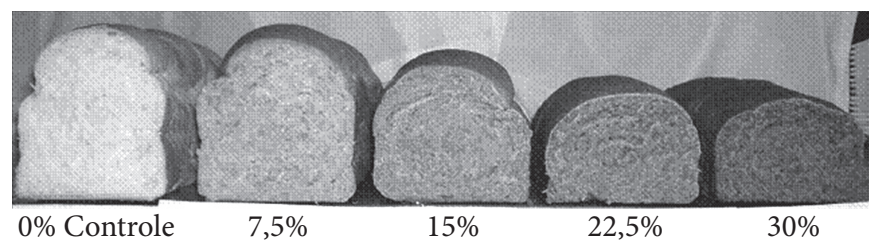

Figura 1. Foto dos pães (corte transversal) com diferentes níveis de substituição de farinha de trigo por farelo de arroz torrado.

Tabela 1. Volume específico e escores médios para a aceitabilidade em relação à aparência, textura e sabor de pães de forma formulados com diferentes níveis de substituição de farinha de trigo (FT) por farelo de arroz torrado (FAT).

\begin{tabular}{lcccccr}
\hline \multirow{2}{*}{ Parâmetro } & \multicolumn{4}{c}{ Tratamento e níveis de substituição de FT por FAT (\%) } & \multicolumn{1}{c}{ CV $^{1}(\%)$} \\
\cline { 2 - 5 } & 0,0 (controle) & 7,5 & 15,0 & 22,5 & 30,0 & \\
\hline Volume específico ${ }^{2,3}$ & $4,43^{\mathrm{A}}$ & $3,68^{\mathrm{B}}$ & $3,48^{\mathrm{B}}$ & $3,12^{\mathrm{C}}$ & $2,70^{\mathrm{D}}$ & 5,93 \\
Aparência & $7,71^{\mathrm{A}}$ & $7,32^{\mathrm{A}}$ & $6,34^{\mathrm{B}}$ & $6,10^{\mathrm{B}}$ & $5,51^{\mathrm{C}}$ & 20,46 \\
Textura & $7,65^{\mathrm{A}}$ & $7,52^{\mathrm{A}}$ & $6,59^{\mathrm{B}}$ & $6,33^{\mathrm{BC}}$ & $6,03^{\mathrm{C}}$ & 19,40 \\
Sabor & $7,36^{\mathrm{A}}$ & $7,08^{\mathrm{A}}$ & $5,96^{\mathrm{B}}$ & $5,18^{\mathrm{C}}$ & $4,51^{\mathrm{D}}$ & 25,12 \\
\hline
\end{tabular}

${ }^{1}$ Coeficiente de variação (\%); ${ }^{2}$ médias seguidas de letras sobrescritas iguais na linha não diferem entre si ao nível de $5 \%$ de probabilidade pelo teste Tukey; $\mathrm{e}^{3} \mathrm{~cm}^{3} . \mathrm{g}^{-1}$. 
obtidos neste trabalho, pois foi observado que o sabor do pão sofreu progressivas alterações indesejáveis com a elevação do nível de substituição da FT por FAT. No entanto, os julgadores não conseguiram diferenciar o sabor do tratamento padrão do tratamento com $7,5 \%$ de substituição, podendo-se então concluir, neste estudo, que este nível de substituição é o ideal. A torração em fogo direto é um processo de difícil controle, que exige constante agitação para que não ocorram escurecimento e formação de compostos amargos, que reduzem a qualidade do produto.

A composição centesimal de um produto exprime, mesmo que seja de forma grosseira, o seu valor nutricional (VILAS BOAS, 1999). Os teores de umidade, cinzas, proteínas, lipídios, carboidratos, fibra alimentar total, fibra alimentar insolúvel, fibra alimentar solúvel e valor calórico dos tratamentos com diferentes níveis de substituição de FT por FAT estão apresentados na Tabela 2 .

Os teores de cinzas, lipídios, fibra alimentar total e fibra alimentar insolúvel aumentaram gradativamente, enquanto o teor de carboidratos digeríveis diminuiu gradativamente com a substituição da FT por FAT. Todos os tratamentos diferiram $(\mathrm{p} \leq 0,05)$ em relação à umidade, com exceção dos tratamentos com 15,0 e 30,0\% de substituição, que não diferiram entre si $(\mathrm{p}>0,05)$. O tratamento que apresentou maior teor de umidade foi de $22,5 \%$ de substituição, seguido pelos tratamentos com 30,0 e $15,0 \%$.Os teores de cinzas médios oscilaram entre 0,90-3,84 g.100 g $\mathrm{g}^{-1}$, sendo que todos os tratamentos diferiram $(p \leq 0,05)$ entre si. Os valores médios de lipídios obtidos foram entre 2,41-5,59 g. $100 \mathrm{~g}^{-1}$, o tratamento controle diferiu $(\mathrm{p} \leq 0,05)$ dos demais tratamentos e os tratamentos entre 7,5 e $22,5 \%$ de substituição não diferiram $(\mathrm{p}>0,05)$ entre si. Todos os tratamentos diferiram $(\mathrm{p} \leq 0,05)$ entre si em relação ao teor de carboidratos, com exceção dos tratamentos com 22,5 e $30,0 \%$ de substituição. Em relação ao teor médio de proteínas, verificaram-se valores de 6,90-8,14 g.100 g ${ }^{-1}$. Os tratamentos controle com 7,5, 15,0 e 30,0\% de substituição não diferiram entre si ( $p>0,05)$, e os tratamentos com 7,5, 15,0, 22,5 e 30,0\% de substituição também não diferiram entre si $(\mathrm{p}>0,05)$.
Em pães de fôrma tradicionais, a umidade situa-se próxima a 30\% (ESTELLER; LANNES, 2005). Em estudo para o desenvolvimento de pão de fôrma sem adição de açúcares, gorduras e emulsificantes, com o uso de enzimas e amido de mandioca modificado, Pontes (2006) citou valores de umidade entre 43,02 e $45,14 \%$, superiores aos obtidos neste trabalho. A umidade aumentou com a elevação do grau de substituição de FT por FAT até o tratamento com $22,5 \%$ de substituição, diminuindo no tratamento com maior nível de substituição. Este aumento na capacidade de retenção de água provavelmente ocorreu devido à elevação dos teores de fibra alimentar total nos pães, até um limite máximo de capacidade de retenção (22,5\% de substituição). A absorção de água por produtos de panificação depende principalmente de dois parâmetros: o conteúdo de proteína e o conteúdo de fibras da massa. A proteína absorve o equivalente a seu peso em água. As fibras têm uma grande capacidade de união com a água e podem ser responsáveis pela absorção de água em até um terço do peso da massa (CAUVAIN; YOUNG, 2002). A variação de proteínas em base seca foi pequena, pois os teores de proteínas na farinha de trigo (13,03\% em base seca) e no farelo de arroz torrado $(14,93 \%$ em base seca), segundo a TBCAUSP (2005), são valores muito próximos.

O teor de fibra alimentar total (FAT) variou entre 4,15-7,20 g.100 g-1 a menor média foi observada no tratamento controle, que não diferiu ( $p>0,05)$ dos tratamentos com 7,5 e 15,0\% de substituição de FT por FAT. Todos os tratamentos diferiram $(\mathrm{p} \leq 0,05)$ entre si em relação à fibra alimentar insolúvel (FAI), com exceção dos tratamentos com 7,5 e 15,0\% e dos tratamentos com 15,0 e 22,5\% de substituição. A fibra alimentar solúvel não diferiu $(p>0,05)$ entre os tratamentos, provavelmente devido ao alto coeficiente de variação $(38,3 \%)$ obtido (Tabela 2$)$. Os valores calóricos médios variaram entre 234,69 e 272,49 kcal.100 g $\mathrm{g}^{-1}$, sendo que todos os tratamentos diferiram $(\mathrm{p} \leq 0,05)$ entre si. A adição de fibras a produtos panificados é a forma mais tradicional para a redução do valor calórico da preparação, atribuindose também a estes alimentos propriedades benéficas à saúde (BENASSI; WATANABE; LOBO, 2001).

De acordo com a Tabela Brasileira de Composição de Alimentos da USP (TBCAUSP, 2005), o pão de fôrma

Tabela 2. Características químicas (base úmida) e valor calórico dos pães de forma elaborados com diferentes níveis de substituição de farinha de trigo (FT) por farelo de arroz torrado (FAT).

\begin{tabular}{|c|c|c|c|c|c|c|}
\hline \multirow[t]{2}{*}{ Componente } & \multicolumn{5}{|c|}{ Tratamentos com seus níveis de substituição de FT por FAT (\%) } & \multirow[t]{2}{*}{$\mathrm{CV}^{1}(\%$} \\
\hline & 0 (controle) & 7,5 & 15,0 & 22,5 & 30,0 & \\
\hline Umidade $^{2,3}$ & $29,84 \pm 0,20^{\mathrm{D}}$ & $32,29 \pm 0,18^{\mathrm{C}}$ & $36,89 \pm 0,13^{\text {B }}$ & $39,96 \pm 0,15^{\mathrm{A}}$ & $37,28 \pm 0,12^{\mathrm{B}}$ & 0,49 \\
\hline $\operatorname{Cinzas}^{2,3}$ & $0,90 \pm 0,01^{\mathrm{E}}$ & $1,38 \pm 0,05^{\mathrm{D}}$ & $1,73 \pm 0,01^{\mathrm{C}}$ & $2,03 \pm 0,01^{\mathrm{B}}$ & $3,84 \pm 0,03^{\mathrm{A}}$ & 1,29 \\
\hline Lipídios $^{2,3}$ & $2,41 \pm 0,17^{\mathrm{C}}$ & $3,68 \pm 0,30^{\mathrm{B}}$ & $3,61 \pm 0,26^{\mathrm{B}}$ & $3,70 \pm 0,07^{\mathrm{B}}$ & $5,59 \pm 0,30^{\mathrm{A}}$ & 4,76 \\
\hline $\mathrm{CHOs}^{2,3,4}$ & $54,56 \pm 0,36^{\mathrm{A}}$ & $50,00 \pm 0,42^{\mathrm{B}}$ & $44,94 \pm 0,66^{\mathrm{C}}$ & $41,49 \pm 0,84^{\mathrm{D}}$ & $38,89 \pm 1,79^{\mathrm{D}}$ & 2,10 \\
\hline $\mathrm{FAS}^{2,3,7}$ & $1,51 \pm 0,19^{\mathrm{A}}$ & $1,68 \pm 0,05^{\mathrm{A}}$ & $1,37 \pm 0,76^{\mathrm{A}}$ & $1,21 \pm 0,07^{\mathrm{A}}$ & $1,30 \pm 0,62^{\mathrm{A}}$ & 38,30 \\
\hline $\mathrm{VC}^{2,68}$ & $272,49 \pm 1,27^{\mathrm{A}}$ & $262,77 \pm 2,13^{\mathrm{B}}$ & $241,95 \pm 1,53^{\mathrm{C}}$ & $227,23 \pm 0,58^{\mathrm{E}}$ & $234,69 \pm 1,82^{\mathrm{D}}$ & 0,27 \\
\hline
\end{tabular}

${ }^{1}$ Coeficiente de variação; ${ }^{2}$ médias seguidas de letras sobrescritas iguais na linha não diferem entre si ao nível de $5 \%$ de probabilidade pelo teste Tukey; ${ }^{3} \mathrm{~g} .100 \mathrm{~g}{ }^{-1}$; ${ }^{4}$ carboidratos; ${ }^{5}$ fibra

alimentar total; ${ }^{6}$ fibra alimentar insolúvel; ${ }^{7}$ fibra alimentar solúvel; e ${ }^{8}$ valor calórico em kcal. $100 \mathrm{~g}^{-1}$. 
tradicional possui 33,36 g.100 g $\mathrm{g}^{-1}$ de umidade, $10,36 \mathrm{~g} .100 \mathrm{~g}^{-1}$ de proteína, 2,80 g.100 g $\mathrm{g}^{-1}$ de lipídios, 51,44 g.100 g $\mathrm{g}^{-1} \mathrm{de}$ carboidratos, 2,04 g.100 g $\mathrm{g}^{-1}$ de cinzas e 2,64 g.100 $\mathrm{g}^{-1}$ de fibra alimentar. Neste trabalho, o tratamento controle obteve médias menores de umidade 29,84 g. $100 \mathrm{~g}^{-1}$, proteínas (8,19\%), lipídios 2,41 g.100 g $\mathrm{g}^{-1}$, cinzas $0,90 \mathrm{~g} .100 \mathrm{~g}^{-1}$ e valores maiores de fibra alimentar total 4,15 g.100 g-1 e carboidratos 54,56 g.100 gProvavelmente, estas defasagens devem-se às possíveis diferenças nas formulações dos pães.

O tratamento com 7,5\% de substituição de FT por FAT (nível considerado ideal pelo teste de aceitabilidade) em relação ao tratamento controle sofreu redução nos teores de proteínas $(8,84 \%)$ e carboidratos $(8,36 \%)$ e no valor calórico $(3,57 \%)$, e aumento nos teores de cinzas (53,33\%), lipídios (52,70\%), fibras totais $(26,02 \%)$, fibras insolúveis $(34,85 \%)$, fibras solúveis $(11,26 \%)$ e umidade $(8,21 \%)$. Uma porção de $100 \mathrm{~g}$ de pão de fôrma (ao redor de 4 fatias) com 7,5\% de substituição de FT por FAT fornece para adultos 38,46\% da ingestão dietética recomendada (IDR) de carboidratos, $13,76-24,90 \%$ de fibras (mulher e homem, respectivamente) e 13,29\% das calorias necessárias para uma dieta de 2000 kcal (IOM, 2005). Além disto, o pão de fôrma torna-se mais rico em fibras e na fração lipídica, rica em orizanol (YOKOYAMA, 2001), portanto, com maior valor funcional e muito pouco prejuízo do valor nutricional (proteínas e carboidratos digeríveis).

Segundo o Ministério da Saúde (BRASIL, 1998), um alimento sólido pode ser considerado como fonte de fibra quando possui um mínimo de $3,0 \mathrm{~g} .100 \mathrm{~g}^{-1}$ de fibras e como de alto teor de fibras quando contém no mínimo $6 \mathrm{~g} .100 \mathrm{~g}^{-1}$. Assim, o tratamento com $7,5 \%$ de substituição da FT por FAT pode ser considerado como fonte de fibras 5,23 g. $100 \mathrm{~g}^{-1}$. Apesar do conhecimento sobre fibras alimentares e suas propriedades relacionadas à promoção da saúde, estudos indicam que a ingestão pela população brasileira tem diminuído (LAJOLO et al., 2001). A adição de fibras em alimentos tem sido uma alternativa encontrada para compensar a deficiência existente na dieta (IOM, 2001).

A obesidade é atualmente um problema de saúde pública em vários países, e é decorrente, dentre outros fatores, da ingestão de alimentos altamente energéticos, ricos em carboidratos simples e gorduras. A utilização de produtos com maior conteúdo de fibras e menor valor calórico é recomendada para a prevenção e controle desse problema (CUPPARI, 2005). Sendo assim, pães de fôrma formulados com 7,5\% de substituição de FT por FAT, aceitos sensorialmente, podem ser uma alternativa viável de inclusão de um produto fonte de fibras no mercado consumidor.

\section{Conclusões}

Quanto maior a substituição de farinha de trigo por farelo de arroz torrado, menor foi o volume específico do pão de fôrma resultante.

O pão de fôrma com $7,5 \%$ de farelo de arroz torrado apresentou a maior aceitação entre os tratamentos com inclusão de farelo de arroz torrado, principalmente em relação à textura e ao sabor.
Os teores de cinzas, fibra alimentar total e fibra alimentar insolúvel aumentaram gradativamente, enquanto o teor de carboidratos diminuiu gradativamente com a substituição da farinha de trigo por farelo de arroz torrado.

Pães de fôrma formulados com 7,5\% de substituição de farinha de trigo por farelo de arroz torrado podem ser uma alternativa viável de inclusão de um produto fonte de fibras no mercado consumidor.

Com novos estudos, utilizando-se outros tratamentos térmicos, que possibilitem melhor controle das variáveis de processamento, como a extrusão termoplástica, será possível produzir farelo de arroz estabilizado mais claro e com menos sabor amargo, o que poderia viabilizar maiores níveis de substituição da farinha de trigo por farelo de arroz.

\section{Referências bibliográficas}

ALENCAR, M. L. C. B.; ALVARENGA, M. G. Farelo de arroz (I): composição química e seu potencial como alimento. Arquivos de Biologia e Tecnologia, v. 34, n. 1, p. 95-9 108, 1991.

Association of Official Analytical Chemists International - AOAC. Official Methods of Analysis. 16 ed. Maryland, 1997. 1014 p.

BARBER, S.; BARBER, C. B.; MARTÍNEZ, J. Proteínas del salvado de arroz. II. Valor potencial de las fracciones de salvado de arroz como ingredientes de alimentos protéics. Revista de Agroquímica y Tecnologia de Alimentos, v. 21, n. 2, p. 247-258, 1981.

BENASSI, V. T.; WATANABE, E.; LOBO, A. R. Produtos de panificação com conteúdo calórico reduzido. Boletim Centro de Pesquisa e de Processamento de Alimentos, v. 19, n. 2, p. 225-242, 2001.

BRASIL. Agência Nacional de Vigilância Sanitária - ANVISA. Portaria n²7, de 13 de janeiro de 1998. Aprova o regulamento técnico referente à informação nutricional complementar. Brasília: ANVISA, 1998. Disponível em: < http://www.anvisa.gov.br/elegis/>. Acesso em: Abril 2008.

CARVALHO, C. W. P. Uso de farelo de arroz na produção de biscoito tipo amanteigado. Viçosa, 1995. 114 p. Dissertação (Mestrado em Ciência e Tecnologia de Alimentos) - Universidade Federal de Viçosa - UFV.

CARVALHO, J. L. V.; BASSINELLO, P. Z. Aproveitamento Industrial. In: SANTOS, A. B.; STONE, L. F.; VIEIRA, N. R. (Ed.). A cultura do arroz no Brasil. 2 ed. Santo Antônio de Goiás: Embrapa Arroz e Feijão, 2006. 1118 p.

CAUVAIN, S. P.; YOUNG, L. S. Fabricación de Pan. 1 ed. Zaragoza: Editorial Acribia, 2002. 440 p.

CUPPARI, L. Guia de nutrição: nutrição clínica no adulto. 2 ed. Barueri: Manole, 2005. 474 p.

ESTELLER, M. S.; LANNES, S. C. S. Parâmetros complementares para fixação de identidade e qualidade de produtos panificados. Ciência e Tecnologia de Alimentos, v. 25, n. 4, p. 802-806, 2005.

FARIA, E. V.; YOTSUYANAGI, K. Técnicas de Análise Sensorial. 1 ed. Campinas: ITAL - LAFISE, 2002. 63 p.

Food and Agriculture Organization - FAO. Economic and 1 social department: the statistic division. 2005. Disponível em: <http:// www.fao.org/es/ess/top/commodity.html?lang=es\&item=27\&yea $r=2005>$. Acesso em: Novembro 20006.

GUTKOSKI, L. C. et al. Efeito de 8 ingredientes na qualidade da massa de pão de forma congelada não fermentada durante o armazenamento. Ciência e Tecnologia de Alimentos, v. 25, n. 3, p. 460-467, 2005. 
Institute of Medicine - IOM. Dietary reference intakes for energy, carbohydrate, fiber, fat, fatty acids, cholesterol, protein and amino acids. Washington: National Academy Press, 2005. 1331 p.

Institute of Medicine - IOM. Dietary reference intakes: proposed definition of dietary fiber. Washington: National Academy Press, 2001. $74 \mathrm{p}$.

Instituto Adolfo Lutz - IAL. Normas analíticas do Instituto Adolfo Lutz: métodos físico-químicos para análise de alimentos. 4 ed. Brasília: Ministério da Saúde, Agência Nacional de Vigilância Sanitária, 2005. 1018 p.

LAJOLO, F. M. et al. Fibra dietética en Iberoamérica: tecnología y salud. São Paulo: Varela, 2001. 469 p.

NABESHIMA, E. H. et al. Propriedades tecnológicas e sensoriais de pães fortificados com ferro. Ciência e Tecnologia de Alimentos, v. 25 , n. 3 , p. $506-511,2005$.

PIMENTEL-GOMES, F. Curso de estatística experimental. Piracicaba: Degaspari, 2000. 477 p.

PONTES, A. E. R. Desenvolvimento de pão de forma sem adição de açúcares gorduras e emulsificantes, com uso de enzimas e amido de mandioca modificado. Campinas, 2006. 83 p. Dissertação (Mestrado em Tecnologia de Alimentos) - Universidade Estadual de Campinas - UNICAMP.

SAUNDERS, R. M. The properties of rice bran as a foodstuff. Cereal Foods World, v. 35, n. 7, p. 632-636, 1990.
SILVA, M. A.; SANCHES, C.; AMANTE, E. R. Prevention of hydrolytic rancidity in rice bran. Journal of Food Engineering, v. 75, n. 4, p. 487-491, 2006.

SILVA, M. R.; SILVA, M.; CHANG, Y. K. Utilização da farinha de jatobá (Hymenaea stigonocarpa Mart.) na elaboração de biscoitos tipo cookie e avaliação de aceitação por testes sensoriais afetivos univariados e multivariados. Ciência e Tecnologia de Alimentos, v. 18, n. 1, p. 25-34, 1998.

SOARES JÚNIOR, M. S. et al. Otimização da formulação de pães de forma preparados com diferentes proporções de farinha de trigo, fécula de mandioca e Okara. Boletim Centro de Pesquisa e de Processamento de Alimentos, v. 24, n. 1, p. 221-248, 2006.

USP. Tabela Brasileira de Composição de Alimentos da Universidade de São Paulo - TBCA-USP. Disponível em: <http://www.fcf.usp. br/tabela>. Acesso em: Agosto 2007.

VILAS BOAS, E. V. B. Alimentos e Nutrientes. Lavras: UFLA, FAEPE, 1999. $74 \mathrm{p}$.

WILSON, E. D.; SANTOS, A. C.; VIEIRA, E. C. Energia. In: OLIVEIRA, J. E. D.; SANTOS, A. C.; WILSON, E. D. Nutrição básica. São Paulo: Savier, $1982.80 \mathrm{p}$.

YOKOYAMA, W. H. Plasma cholesterol lowering by rice bran oryzanols, sistosterolestersand cholestryramine in hamsters with predominantly LDL lipoprotein cholesterol. In: THE RICE UTILIZATION WORKSHOP, 2001, New Orleans, EUA. Proceedings... Houston: USDA, 2001. p. 6-7. 